\title{
Comment
}

\section{O Desafio da Leitura e da Escrita em Crianças com Perturbação do Espectro do Autismo}

\author{
Caroline Maria Tavares de Sampaio $^{1}$; Gislene Farias de Oliveira ${ }^{2}$
}

\begin{abstract}
Resumo: O Transtorno do Espectro Autista é uma desordem do desenvolvimento do cérebro, antes, durante ou logo após o nascimento, que afeta a capacidade de comunicação social. O presente estudo bibliográfico, objetiva discutir as características comuns em crianças autistas, identificando as suas potencialidades e as suas necessidades especiais, no que tange à leitura e escrita. Os resultados demonstraram que as crianças autistas precisam muito do afeto e da atenção constante dos pais, para se desenvolverem de maneira saudável, vencendo os obstáculos necessários para o seu progresso cognitivo, social e intelectual. Verificou-se também a grande importância de que o diagnóstico seja dado o mais rapidamente possível, para que todas as necessidades especiais do aluno possam ser supridas no tempo adequado, com a ajuda dos profissionais indicados. Concluiuse que, nem todas as crianças autistas conseguirão as condições necessárias para o domínio da leitura e da escrita, visto que existem graus muito severos da síndrome. Porém, em muitos casos, se bem amparadas, as crianças autistas poderão desenvolver estas habilidades linguísticas. O que se faz necessário é que elas sejam devidamente estimuladas, para que possam aprender o que lhes for possível destas competências linguísticas fundamentais para o desenvolvimento pleno do ser humano.
\end{abstract}

Palavras-chave: Autismo; Desenvolvimento infantil; Leitura e Escrita.

\section{The Challenge of Reading and Writing in Children with Autism Spectrum Disorder}

\begin{abstract}
Autism Spectrum Disorder is a developmental disorder of the brain, before, during or shortly after birth, which affects the ability of social communication. The present study aims to discuss the common characteristics of autistic children, identifying their potential and their special needs regarding reading and writing. The results showed that autistic children need much of the affection and constant attention of their parents to develop in a healthy way, overcoming the obstacles necessary for their cognitive, social and intellectual progress. Great importance was also perceived in the early diagnosis, so that all the special needs of the student can be met in the appropriate time, with the help of adequate professionals. It was concluded that not all autistic children will achieve the necessary conditions for reading and writing as there are very severe degrees of the syndrome. However, in many cases, if well supported, autistic children will be able to develop these language skills. What is needed is that they be properly stimulated, in order to learn what they can from these linguistic skills, fundamental to the full development of the human being.
\end{abstract}

Keywords: Autism; Child development; Reading and writing.

\footnotetext{
${ }^{1}$ Graduada em Letras pela Universidade Regional do Cariri - URCA (Crato/CE 2007). Mestranda pela Anne Sullivan University UNISULLIVAN. Especialista em Linguística Aplicada ao Ensino da Língua Portuguesa pela FAFIRE (Recife/PE 2008 - 2009). Professora do semi-internato no Colégio Nossa Senhora de Fátima, localizado em Barbalha-CE. Contato: carolsampaio80@gmail.com;

${ }^{2}$ Doutorado em Psicologia Social pela UFPB. Pós doutorado em Ciências da saúde - FMABC-SP. Contato: gislenefarias@gmail.com.
} 


\title{
Introdução
}

A perturbação do espectro do autismo muitas vezes não é identificada nos primeiros meses de vida da criança. É comum, em muitos casos, o diagnóstico da síndrome só ser comprovado na idade escolar, quando a interação social da criança aumenta consideravelmente (CUNHA, 2015). Sobre esta perturbação, é importante entender:

\begin{abstract}
As características observadas na síndrome do autismo variam na forma de exteriorização dos desvios de relações interpessoais, linguagem, motricidade, percepção e patologias associadas ao distúrbio. A intensidade destes desvios, os estados mais determinantes, também é diversificada. As alterações do comportamento social são marcadas pela acentuada inaptidão de desenvolver relações com outras pessoas, pois os autistas preferem permanecer isolados do grupo social. Investigações recentes confirmam que as relações dos autistas com os objetos inanimados seguem um entendimento incomum ou se apegam em demasia ou os abandonam (RODRIGUES e SPENCER, 2015, p. 21-22).
\end{abstract}

A síndrome do autismo apresenta muitas variações, tanto na maneira de externar os desvios apresentados como na intensidade destes desvios. Essa grande variação de sintomas faz do autismo uma perturbação difícil de ser diagnosticada. Pois, as crianças autistas podem apresentar características bem diferentes entre si.

O infante portador desta perturbação normalmente apresenta características como: esquivar-se de relações pessoais; não conseguir manter contato visual; não se adaptar a mudanças de rotina; apresentar hiperatividade física; concentrar-se no seu mundo interior, desligando-se do ambiente externo; apresentar agitação desordenada; não responder a chamados; não exteriorizar medo diante de perigos; apresentar birras; evitar o contato físico; não se adequar a metodologias de ensino; apresentar ecolalias; apresentar calma exagerada; realizar movimentos no corpo em forma de círculo; apegar-se estranhamente a objetos e utilizá-los de maneira errada; ser sensível a barulhos; apresentar estereotipias; demonstrar dificuldade para captar sentimentos e aspectos subjetivos de uma conversa, por interpretar tudo ao pé da letra. O indivíduo com a perturbação, certamente, apresentará alguns destes comportamentos.

A criança com a perturbação do espectro autista não segue um padrão de comportamento igual durante toda a sua vida. De acordo com a idade, ela poderá apresentar 
alterações consideráveis na sua maneira de ser. Decorre deste fato, a grande dificuldade de se diagnosticar precocemente a síndrome. A esse respeito, é conveniente acrescentar:

\begin{abstract}
Observamos que, na maioria das vezes, a criança com essa síndrome, no período que vai do nascimento até o primeiro ano de vida, era calma, excessivamente tranquila, "muito boazinha" ou, ao contrário disso, irrequieta, chorando muito e com problemas relacionados ao sono. Do primeiro ano de vida até o segundo, é relatado que demorou a andar, demorou a falar e quando falou, repentinamente, sua fala cessou. A partir do segundo ano de vida, passou a apresentar comportamentos estranhos. Dizem: "Ele é esquisito". O período do reconhecimento de uma possível síndrome é obscuro e demorado, tanto pela parte dos pais como por muitos médicos, em virtude da complexidade do quadro, pela falta de informações básicas sobre síndromes não identificadas por meio de exames laboratoriais, impedindo de haver um processo de intervenção mais precoce e claro. Desta forma, tornam-se raros tais diagnósticos antes dos 12 meses de idade (ORRÚ, 2012, p. 31).
\end{abstract}

Não existe nada, em particular, que consiga denunciar a presença desta perturbação na criança portadora. Muitas vezes a criança é matriculada na escola, sem que a mãe nem desconfie que ela apresente problemas. Por isso, o professor infantil deve demonstrar toda a dedicação possível aos seus pequenos alunos. Pois, muitas vezes, é ele que percebe as características estranhas e informa aos pais e diretores. Pode até acontecer de alguns pais, até de propósito, fecharem os olhos para algum sinal de diferença no comportamento dos filhos.

A observação atenta do professor é de extrema importância para que a criança autista possa ser tratada de acordo com as suas singularidades comportamentais. É preciso conhecer o aluno para que o seu desenvolvimento seja estimulado da maneira mais conveniente. $\mathrm{O}$ fato da síndrome poder apresentar características diversas em crianças portadoras, exige do professor atenção redobrada. De acordo com o que foi dito, deve-se evidenciar:

A formação do educador e o seu conhecimento científico a respeito do assunto tornam-se essenciais para a identificação da síndrome. Da mesma sorte, sua capacitação pedagógica no exercício docente possibilitará uma educação adequada. Apesar de níveis de comprometimentos dissimilares, é comum o aluno com autismo apresentar algumas características mais marcantes que inicialmente poderão interferir na sua aprendizagem: o deficit de atenção, a hiperatividade, as estereotipias e os comportamentos disruptivos. O que fazer diante delas? O primeiro passo a ser dado pelo professor será o de conhecer seu aluno, seus afetos, seus interesses. Isso possibilitará a instituição de exercícios, atividades e afazeres que ajudarão a canalizar a sua atenção. Com efeito, a partir do princípio afetivo da atividade pedagógica, o professor encontrará recursos para a superação do quadro de hiperatividade e de deficit de atenção. Não se trata de uma regra, mas de um caminho, pois o afeto traz o interesse para os movimentos de ensino e aprendizagem. Quais atividades o aluno gosta de fazer? Como utilizá-las para desenvolver sua atenção? São perguntas que irão ser respondidas nesse percurso (CUNHA, 2015, p. 25). 
Identificar os interesses dos alunos autistas, o que lhes chama a atenção, servirá bastante para que o professor possa planejar as suas intervenções pedagógicas. Pois, é preciso relacionar os afetos dos alunos com as estratégias utilizadas nos planos de aula, para que a aprendizagem possa ser construída com sucesso.

\section{As principais características da criança com PEA e a repercussão destas características na maneira de aprender}

As crianças com necessidades especiais aprendem quando estão interessadas, quando acham que a atividade é prazerosa e divertida. Mas o aprendizado só poderá acontecer de acordo com o nível de desenvolvimento da criança. O professor tem que estimulá-las a perceber a leitura e a escrita como sendo atividades empolgantes que lhes ajudarão a entender melhor várias situações da vida. Estas habilidades linguísticas devem ser encaradas pelos infantes como coisas interessantes. Para que isso aconteça, é preciso que o professor lhes mostre como elas poderão ajudá-los nas aventuras do dia a dia (CUNHA, 2015). De acordo com o que foi dito, é interessante lembrar que:

[...] a leitura e a escrita resultam de experiência social, cultural, cognitivas e linguísticas. A escola é, sem dúvida, um espaço essencial para o letramento. Essa ideia ganha bastante relevância no ensino do aprendente com autismo, independentemente do nível do comprometimento. Porém, é preciso salientar que a ênfase dessa prática não pode estar centrada somente no processo de aquisição de códigos alfabéticos e numéricos mas também, acima de tudo, nas experiências e vivências socioculturais, familiar e escolar. Trata-se da aprendizagem da leitura do mundo, como diz Freire (CUNHA, 2015, p. 81).

É importante que o professor faça com que a criança autista sinta vontade de descobrir coisas que fazem parte do seu mundo, através da leitura ou da escrita. Se o aprendizado destas modalidades da língua for explorado nas situações precisas da vida do menor, muito provavelmente, ele evoluirá facilmente nas suas conquistas intelectuais. O professor deve estar sempre antenado nas ações dos seus alunos, para que, assim, ele possa intervir nos momentos apropriados.

De acordo com o pensamento de Cunha (2015), o docente precisa saber que, para a criança autista evoluir de forma saudável, ele não deve se alterar nem valorizar as suas 
reações excessivas. É importante que o professor se empenhe em disciplinar a atividade, sem imobilizar a criança. Pois, ela deve confiar no seu mestre. O docente precisa estar sempre atento para que, assim, possa redirecionar a atenção e a ação do estudante, todas as vezes em que este se desviar do foco da aprendizagem. Além disso, o professor necessita ter em mente que, durante as suas aulas, ele deve falar baixo, sem nunca alterar o tom de voz nem o contato visual. As correções que precisarem ser feitas devem ser sempre de forma instrutiva, ensinando a maneira certa sem reprimir a criança. Certamente, estas alternativas pedagógicas contribuirão bastante para que as aulas cumpram o seu papel.

\section{A Leitura como processo cognitivo}

Para que se possa falar sobre a leitura como processo cognitivo, antes é preciso definir o termo "cognição". De maneira geral, a cognição pode ser entendida como sendo o papel da inteligência, quando se adquire um conhecimento. Em outras palavras, a cognição é a capacidade que cada pessoa tem para processar um conhecimento e transformá-lo em aprendizagem. Sobre o significado da palavra "cognição", pode-se acrescentar:

[...] ato ou efeito de conhecer 1 processo ou faculdade de adquirir um conhecimento 2 p. ext. percepção, conhecimento [...] 4 psic. conjunto de unidades de saber da consciência que se baseiam em experiências sensoriais, representações, pensamentos e lembranças 5 psic. série de características funcionais e estruturais da representação ligadas a um saber referente a um dado objeto [...] (HOUAISS e VILLAR, 2001, p. 754).

Tentar entender a leitura como processo cognitivo é procurar entender todo o processo de aquisição dos conhecimentos necessários ao aprendizado da leitura. Para que isso aconteça, primeiramente, é importante que seja esclarecido o que é "saber ler", o que significa desvendar o código escrito ou qualquer outro tipo de enigma, na busca pela melhor compreensão da vida.

Existem duas definições sobre o processo da leitura que são bem claras e verdadeiras. Numa visão mais restrita, ler consiste em saber relacionar as letras do alfabeto com seus respectivos sons, para que daí se possa produzir significados. Já num sentido mais abrangente, a leitura é vista como sendo o estabelecimento de uma relação entre um símbolo e um significado. A definição mais ampliada de leitura a entende não apenas como a de palavras 
escritas, mas também a de qualquer outro símbolo, como gestos, cores, sinais da natureza, que transmita alguma mensagem.

Os conceitos de leitura expostos acima descrevem este processo como sendo a capacidade de captar o sentido de cada traço que a vida deixa impresso. É como se o cérebro de cada pessoa guardasse representações do mundo e as acionasse sempre que preciso, para melhor entender a realidade. Para explicar esse sistema de formação e evocação das memórias, é importante citar:

Ao converter a realidade em um complexo código de sinais elétricos e bioquímicos, os neurônios traduzem. Na evocação, ao reverter essa informação para o meio que nos rodeia, os neurônios reconvertem sinais bioquímicos ou estruturais em elétricos, de maneira que novamente nossos sentidos e nossa consciência possam interpretálos como pertencendo a um mundo real (IZQUIERDO, 2002, p. 17).

A mente humana está o tempo todo entrando em contato com a realidade e, nesse contato, ela tanto precisa interpretá-la como também transmiti-la para os seus semelhantes. Essa leitura e difusão da realidade são fatores decisivos para a vida em sociedade. E estes só são possíveis como consequência dos processos cognitivos que acontecem constantemente no cérebro humano, permitindo, por exemplo, que o leitor proficiente não enxergue as letras individualmente, mas sim as palavras e o significado delas.

O leitor proficiente é aquele que pode se voltar totalmente para a construção do sentido do texto, já que, para ele, a decifração do código não é mais encarada como um obstáculo. Porém, esta capacidade para a leitura não é uma característica inata nos seres humanos, é uma habilidade construída a partir de um longo processo de alfabetização e letramento. A este respeito, é interessante adicionar:

Compreender bem um texto não é uma atividade natural nem uma herança genética; nem uma ação individual isolada do meio e da sociedade em que se vive. Compreender exige habilidade, interação e trabalho. Na realidade, sempre que ouvimos alguém ou lemos um texto, entendemos algo, mas nem sempre essa compreensão é bem-sucedida. Compreender não é uma ação apenas linguística ou cognitiva. É muito mais uma forma de inserção no mundo e um modo de agir sobre o mundo na relação com o outro dentro de uma cultura e uma sociedade. Para se ter uma ideia da dificuldade de compreender bem basta considerar que em menos da metade dos casos as pessoas se saem a contento nos testes realizados em aula ou em concursos, o que se repete em muitas situações da vida diária. É comum ouvirmos reclamações do tipo: "Não foi bem isso que eu quis dizer"; "você não está me entendendo"; "o autor não disse isso", e assim por diante. Contudo, vale a pena indagar-se o que é que estava sendo dito ou o que é que o autor queria dizer. Existem, pois, má e boa compreensão, ou melhor, más e boas compreensões de um 
mesmo texto, sendo estas últimas atividades cognitivas trabalhosas e delicadas (MARCUSCHI, 2008, p. 229-230).

A capacidade para a leitura e compreensão de textos escritos ou falados não é uma característica pré-determinada no cérebro de cada ser humano. Esta capacidade só se desenvolve em um sujeito, quando este exerce a prática da leitura e vive em sociedade, podendo a todo momento entrar em contato com outras pessoas. É preciso que exista constância na arte de ler e compreender. Se a leitura acontecer apenas em raras ocasiões, o indivíduo, provavelmente, não conseguirá adquirir essa habilidade.

Sempre que ouvimos alguém ou lemos algo, interpretamos o que lemos ou ouvimos. Mas nem sempre esta interpretação condiz com o texto em questão. A compreensão muitas vezes não é feliz. $\mathrm{O}$ ato de compreender, muito mais do que uma atividade puramente linguística e cognitiva, é uma maneira de se encontrar no mundo e de atuar sobre este mundo, através das relações sociais. Existem interpretações péssimas, assim como existem também interpretações vitoriosas de um mesmo texto. A boa compreensão é um trabalho cognitivo difícil e esmerado, que exige bastante atenção.

Um aspecto que contribui bastante para o sucesso na compreensão de textos é a extensão do vocabulário conhecido; quanto maior o número de palavras que se domina em um texto, mais fácil será a sua compreensão. Pois, o tempo gasto na decodificação de palavras desconhecidas desvia a atenção do sujeito para o que mais importa na leitura, que é a compreensão do texto. De acordo com o que foi relatado acima, pode-se afirmar:

\footnotetext{
A rapidez com que os sujeitos leem palavras familiares, como "gato", e a dificuldade com que leem as menos frequentes, como "inconstitucionalissimamente", são fatores que contribuem para a qualidade da compreensão leitora. Dedicar mais tempo à "decodificação" das palavras desvia a atenção do leitor para o significado delas. Significa que, quanto mais rico o vocabulário frequente do leitor, menos atenção à decodificação ele empreenderá e mais se voltará para o significado da palavra, o que contribuirá para a qualidade da compreensão (BITTENCOURT, CARVALHO, JUHAS e SCHWARTZ, 2015, p. 15).
}

O hábito de ler é fator imprescindível para que o sujeito desenvolva a capacidade para a compreensão leitora. Pois, quanto mais se pratica a leitura, mais se acumula o vocabulário e, desta forma, a atenção do leitor fica cada vez mais voltada para o significado do texto. E saber ler, muito mais do que saber transformar o código escrito em som, é conseguir captar o sentido verdadeiro do texto, é obter êxito na compreensão textual. 
O sujeito precisa superar três obstáculos para conseguir desenvolver a compreensão leitora. Primeiramente, é preciso adquirir a capacidade de transformar um texto escrito em oral e depois captar o significado do texto. A segunda barreira a ser vencida consiste em aprender a utilizar o texto escrito para se comunicar e para compreender o que as outras pessoas querem dizer. O terceiro obstáculo é adquirir a capacidade para relacionar o obstáculo um, reconhecer o som e o significado das palavras, com o obstáculo dois, que diz respeito à capacidade para se comunicar através de textos. Esta relação entre os dois primeiros obstáculos poderá levar o sujeito a compreender os textos que lê. A cerca do que foi exposto, é conveniente acrescentar:

\begin{abstract}
Para alcançar a compreensão leitora, o sujeito, teoricamente, precisa passar por três desafios relacionados com a aprendizagem da linguagem escrita: o primeiro consiste na aprendizagem da habilidade de passar da ortografia das palavras, para a fonologia e dessa para o significado, ou, no caso da escrita, da fonética para a ortografia. Essas são habilidades específicas e correspondem ao que geralmente denominamos "mecânica" da leitura ou "reconhecimento das palavras" (SAN-CHEZ MIGUEL, 2004, p. 7). O segundo desafio supõe utilizar essas habilidades para nos comunicar por escrito e para compreender o que os outros comunicam. Uma comunicação que acontece, geralmente, a distância e que demanda o desenvolvimento de recursos cognitivos sofisticados que ultrapassam as competências linguísticas orais. O desafio "final" corresponde à articulação entre o primeiro - a mecânica da leitura - e o segundo - a habilidade comunicativa. A qualidade que esses dois processos farão entre si encaminhará ou não para a capacidade de compreender os textos que o sujeito lê. O processo do aluno inicia quando compreende o funcionamento do sistema alfabético, consegue decodificar as palavras, frases e textos. Essa aprendizagem não é simples e os indicadores da educação no Brasil têm evidenciado as dificuldades que os professores estão tendo para alcançá-la. Depois de alcançar a compreensão do funcionamento do sistema alfabético, o aluno passa a ser exposto a diferentes tipos de textos, e essas experiências podem contribuir para que ele construa outro tipo de competências que podem ou não, dependendo da qualidade delas, contribuir para a compreensão leitora (BITTENCOURT, CARVALHO, JUHAS e SCHWARTZ, 2015, p. 17-18).
\end{abstract}

A compreensão leitora é o resultado do longo processo de aprendizagem da leitura, que vai desde a aquisição do código escrito até a competência para se comunicar através da língua escrita e para compreender o sentido de um texto lido. A compreensão literal é aquela em que o sujeito apresenta quando consegue captar todas as informações que estão expressas literalmente no texto. Na compreensão interpretativa, o leitor usa as informações presentes no texto e as relaciona com seus conhecimentos prévios, para que, desta forma, possa construir o significado do texto. Por último, tem-se a compreensão crítica do texto, que se refere à capacidade para construir um juízo de valor sobre o que foi dito. Neste nível de compreensão, 
o leitor compara as informações do texto com aquelas que aparecem em outros documentos escritos já conhecidos, ou mesmo compara o que o texto diz com as suas próprias experiências de vida, seus conhecimentos e valores. Para que, a partir daí, possa construir um julgamento sobre o que foi lido.

Quanto mais se avança neste caminho rumo ao letramento, a maneira de enxergar o código escrito da língua vai se modificando. Adotando-se a leitura como prática diária, a decifração do código escrito vai se tornando automática. Esse processo de desenvolvimento da leitura só é possível nos seres humanos devido à capacidade de construir significados a partir de símbolos. Esta capacidade não é percebida em nenhum outro ser vivo, além do homem. Como prova disso, pode-se lembrar que em qualquer grupo social humano existe alguma forma de linguagem, ainda que possa não haver um código escrito.

Para que um leitor possa compreender um texto escrito, ele precisa elaborar uma representação mental adequada para o texto. Porém, existem vários fatores que podem vir a prejudicar esta representação mental ou até impedi-la de ser criada. Dentre os aspectos que podem dificultar a compreensão de um texto escrito, estão a falta de intimidade com o código escrito e a ausência de conhecimento prévio sobre o assunto abordado no texto.

\section{A criança autista e a leitura cognitiva}

A síndrome do autismo pode se manifestar de forma bem variada de pessoa para pessoa, ou seja, os sintomas desta perturbação aparecem em graus distintos em cada indivíduo acometido. Uma pessoa autista pode apresentar graves dificuldades na interação social, não falar e ter deficiências cognitivas bem acentuadas, enquanto que outra pessoa autista pode apresentar apenas leves perturbações que sejam até imperceptíveis para pessoas que desconhecem a síndrome. Essa variação no jeito de ser de cada indivíduo autista precisa ser levada em consideração quando se pretende ensinar aptidões complicadas, como a leitura.

A criança autista apresenta dificuldades para se comunicar e para interagir socialmente. Estas dificuldades contribuem bastante para que a utilização da língua falada seja afetada. Com isso, a aprendizagem da leitura para a criança autista fica comprometida. Pois, 
aprender a ler, quando não se tem domínio do idioma falado, é uma tarefa bem mais complexa. Em virtude do que foi dito, convém mencionar:

\begin{abstract}
Pessoas com autismo que falam apresentam mais chances de aprender a ler do que crianças com autismo que não falam. A ausência da fala costuma estar relacionada a atraso significativo no desenvolvimento e a maiores déficits cognitivos. Apesar de ter acompanhado em minha trajetória profissional algumas pessoas com autismo que não falavam e que apresentavam habilidades de leitura, na maioria dos casos, a aprendizagem de leitura por essas pessoas é limitada, restringindo-se à aprendizagem de habilidades iniciais e rudimentares. Apesar dessas dificuldades, algumas pessoas não falantes com autismo demonstram grande interesse por palavras escritas; nesse caso, deve-se considerar a possibilidade de ensinar a esses educandos algumas relações entre palavras escritas e figuras do cotidiano, referentes a itens de interesse do aprendiz. Para uma pessoa que não fala, aprender a identificar algumas palavras escritas em seu cotidiano pode melhorar muito a compreensão do ambiente e favorecer a interação social (GOMES, 2015, p. 17).
\end{abstract}

A aquisição da linguagem falada é um fator essencial para que a aprendizagem da leitura possa acontecer de forma plena em um indivíduo. Portanto, para as crianças autistas que não desenvolveram o idioma oral, o desenvolvimento completo da habilidade linguística da leitura será praticamente impossível. Já que as habilidades da fala e da leitura possuem uma ligação indissociável.

Desde o princípio do aprendizado da leitura, a criança é levada a estabelecer relações entre a sua linguagem oral e a linguagem escrita. Este contato é necessário e inevitável para que aconteça o aprendizado. Com relação à aprendizagem da leitura e a sua ligação com a linguagem oral, é válido lembrar:

\begin{abstract}
A criança, ao aprender a ler, precisa começar a concentrar-se no fato de que a linguagem falada consiste de palavras e sentenças separadas. É necessário que ela descubra também que as palavras e as sentenças escritas correspondem a essas unidades da fala. [...] Uma outra habilidade nova que a alfabetização requer da criança é a necessidade de tomar consciência dos fonemas, o que, até o momento da alfabetização, não foi importante para as habilidades linguísticas da criança. [...] A consciência dos fonemas é importante para a aprendizagem da leitura em um sistema de escrita como o nosso, que é um sistema alfabético, porque as letras do alfabeto representam normalmente os fonemas (NUNES, BUARQUE e BRYANT, 2011, p. $8)$.
\end{abstract}

Para que uma criança possa desenvolver a habilidade da leitura, ela começará por aprender que a linguagem escrita é uma tentativa de registrar a linguagem falada. A partir daí, o infante será levado a relacionar palavras faladas com palavras escritas. Então, através destas 
relações, o aprendiz começará a perceber que o idioma oral é representado na escrita por palavras e frases que constituem-se de unidades com significado próprio.

Outro fator, no aprendizado da leitura, que se relaciona com a linguagem oral é o indispensável conhecimento sobre os fonemas da língua. Pois, na língua portuguesa, cada letra do alfabeto corresponde a uma tentativa de representação das menores unidades de som da fala, que são os fonemas. Desta forma, se o aluno consegue distinguir o fonema que cada letra tenta representar, ele terá bem mais possibilidades de sucesso na aprendizagem da leitura.

De acordo com estudos recentes sobre as características da leitura das crianças autistas, percebe-se que estas crianças desenvolvem bem a capacidade de transformar grafemas em fonemas. No entanto, a leitura com compreensão não tem o mesmo êxito nestes infantes. Em virtude do que foi dito, é conveniente acrescentar:

Seguindo as indicações da literatura, procedimentos planejados para o ensino de leitura para pessoas com autismo devem considerar estratégias que favoreçam tanto a leitura oral quanto a leitura com compreensão. A leitura oral fluente [...] pode ser definida como leitura combinatória, que consiste na habilidade de ler qualquer palavra (não apenas palavras diretamente ensinadas) sob controle de unidades intrapalavras e/ou intra sílabas; assim, procedimentos que enfoquem o ensino de sílabas podem favorecer a aprendizagem desse aspecto da leitura. Por outro lado, a leitura com compreensão [...] pode ser identificada quando o aprendiz relaciona o que lê com aspectos do mundo e de sua experiência prévia com eles. Em situação de ensino, esse aspecto da leitura pode ser verificado quando um aprendiz relaciona corretamente figuras às palavras impressas correspondentes, assim como o inverso, e a aprendizagem dessa habilidade ocorre de maneira indireta, derivada de relações entre estímulos (por exemplo, palavra ditada-palavra impressa; palavra ditadafigura) ou entre estímulos e respostas (por exemplo, nomeação de palavra impressa; nomeação de figura) previamente aprendidas. Quando esses estímulos (figuras e palavras) se tornam equivalentes, ou seja, quando passam a fazer parte de uma mesma classe, pode-se dizer que o indivíduo compreende aquilo que lê. [...] (GOMES, 2015, p. 77-78).

A leitura oral corresponde à capacidade de pronunciar corretamente cada palavra escrita, sem necessariamente entender o significado daquilo que se leu. Já a leitura com compreensão diz respeito à habilidade de compreender aquilo que está escrito, conseguindose relacionar as palavras e frases lidas com o seu verdadeiro sentido. Apesar de se ter percebido que a criança autista consegue obter melhor êxito na leitura oral, é importante que se planeje estratégias que favoreçam, para estes infantes, o aprendizado desses dois tipos de leitura. 
As crianças autistas, se bem estimuladas, poderão conseguir desenvolver a habilidade da leitura, ainda que possam apresentar algumas limitações. Os professores precisam encontrar as táticas apropriadas para que estas crianças obtenham resultados eficazes. Para que isso aconteça, é imprescindível que o docente identifique os sintomas que seus alunos apresentam, além de descobrirem o grau em que estes sinais se manifestam em cada criança autista.

Um fator muito importante para que o ensino da leitura seja exitoso para qualquer criança é encontrar meios para chamar-lhe a atenção, através de enunciados fáceis e significativos. O professor que escolher textos adequados para seus alunos praticarem a leitura e fizer isso com constância, certamente, conseguirá que seus pupilos adquiram esta habilidade linguística, ainda que com alguma limitação, decorrente da sua natureza. De acordo com o exposto acima, pode-se afirmar:

O que acontece na sala de aula é crítico, já que pode determinar se as crianças serão leitoras ou não. O professor ou a professora é uma das pessoas mais importantes para motivar, estimular ou, ao contrário, frustrar esta aprendizagem.

As crianças devem compreender que a aprendizagem da leitura tem um sentido. A criança aprende a ler lendo, portanto a professora ou professor deve fazer com que esta aprendizagem seja fácil e divertida, no entanto, existem muitos casos onde são utilizadas formas simples de tornar a leitura mais complicada.

Fazer da leitura uma aprendizagem fácil quer dizer que seja: significativa, útil, divertida e frequente (GÓMEZ e TERÁN, 2014, p. 361).

O docente precisa estar ciente de que os seus métodos utilizados para o ensino da leitura poderão formar ótimos leitores ou, ao invés disso, deixar pessoas desmotivadas para esta tarefa. Pois, são a qualidade dos textos escolhidos pelos professores e a constância com que estes trabalham essa habilidade com os alunos que farão a diferença no aprendizado da leitura.

O professor deve estar sempre atento às potencialidades de seus alunos e aos seus interesses. Para que, desta forma, ele possa escolher com segurança as sugestões de leitura para seus aprendizes. Assim, o docente conseguirá dizer, mais adiante, que não trabalhou em vão; mas, ao contrário, entregou para seus pupilos a chave para que possam mergulhar no mundo das letras e desvendar os seus tantos mistérios. 


\section{Problemáticas no processo de alfabetização de crianças autistas}

Para que se possa falar sobre o processo de alfabetização, se faz necessário que se compreenda, primeiramente, o significado do termo "alfabetização". Falar sobre alfabetização pode ser compreendido como sendo o ato de falar sobre a aprendizagem dos códigos da escrita de uma língua, somada à aprendizagem dos números. Sendo assim, fica fácil perceber que a alfabetização corresponde ao processo de alfabetizar. Como definição da palavra "alfabetização", pode-se citar:

Alfabetização s.f. ato ou efeito de alfabetizar, de ensinar as primeiras letras 1 iniciação no uso do sistema ortográfico $\mathbf{1 . 1}$ processo de aquisição dos códigos alfabético e numérico; letramento $\mathbf{2}$ ato de propagar o ensino ou difusão das primeiras letras (HOUAISS e VILLAR, 2001, p. 150).

O vocábulo "alfabetização" pode ser empregado tanto como sendo um curso que ensina o indivíduo a ler e escrever, como sendo a própria aprendizagem da leitura e da escrita. Uma pessoa é alfabetizada quando ela sabe ler e escrever, mesmo não sabendo fazer uso das funções da escrita no dia a dia.

Há pouco tempo, bastava que uma pessoa tivesse o domínio do código escrito de sua língua para que ela fosse capaz de frequentar qualquer ambiente letrado sem passar por vexames ou apuros. Nessa época, ninguém parava para pensar se tal pessoa sabia como utilizar as inúmeras táticas de leitura e escrita nas situações da vida real. De acordo com o exposto acima, é importante afirmar:

[...] Durante esse período o termo alfabetização se tornava suficiente para designar a aquisição da leitura e escrita e suas implicações. Não se imaginava que um indivíduo alfabetizado não fosse capaz de utilizar o sistema de escrita em suas atividades diárias. O analfabeto funcional não era identificado neste contexto. Novos olhares, porém, foram lançados sobre este assunto e o conceito de alfabetização passou a se tornar insuficiente para designar as novas ideias e constatações que envolvem esse tema, uma vez que se passou a perceber que a simples aquisição do código escrito não era o suficiente para que o sujeito fizesse uso das funções sociais da escrita. Surgem novos termos que ampliam o conceito de alfabetizado e de alfabetização; entre eles, surge o conceito de letramento com o objetivo de diferenciar a ação de alfabetizar, das práticas sociais da leitura e da escrita (KLEIMAN, 1995) (apud cit MARQUES, 2013, p. 207).

Dizer que alguém é alfabetizado não é suficiente para provar que a pessoa está apta para utilizar o código escrito nas situações do cotidiano. Atualmente, para o indivíduo que 
consegue se beneficiar do código escrito no dia a dia existe o termo "letrado". Já a expressão "analfabeto funcional” é usada para o sujeito que sabe ler e escrever, mas não tem habilidade para empregar o código escrito na sua rotina diária.

Os objetivos expostos nos planos escolares, para o ensino da leitura e da escrita, são bastante abstratos e afastados da realidade. A partir de frases como "alcançar o prazer da leitura", "ser capaz de expressar-se por escrito", as crianças não podem captar as utilidades destes conhecimentos para a vida real. Dessa forma, as inúmeras razões para que se aprenda a ler e escrever ficam acessíveis apenas para as crianças que possuem núcleos familiares letrados. Pois, somente estas têm a possibilidade de ver o código escrito sendo utilizado rotineiramente.

É imprescindível para os cursos de alfabetização de crianças que as funções sociais da língua escrita sejam evidenciadas e praticadas. Pois, para que a aprendizagem seja frutífera e eficaz, os estudantes mirins precisam sentir-se motivados para aprender. Porém, nas aulas de língua não são mencionadas as possíveis utilidades desta no cotidiano. Sendo assim, os alunos que crescem em famílias com níveis baixos ou até nulos de alfabetização, sem encontrarem motivos reais para aprenderem o código escrito da língua, vão se tornando, na sua maioria, analfabetos funcionais. Já que não têm a oportunidade de vivenciar nem com seus familiares nem com seus professores e colegas os benefícios que a língua escrita pode trazer. A este respeito, é válido mencionar:

\begin{abstract}
Um dos objetivos sintomaticamente ausente dos programas de alfabetização de crianças é o de compreender as funções da língua escrita na sociedade. Como as crianças chegam a compreender essas funções? As crianças que crescem em famílias onde há pessoas alfabetizadas e onde ler e escrever são atividades cotidianas, recebem esta informação através da participação em atos sociais onde a língua escrita cumpre funções precisas. Por exemplo, a mãe escreve a lista de compras do mercado, a mãe leva consigo essa lista e a consulta antes de terminar suas compras: sem querer, está transmitindo informações sobre uma das funções da língua escrita (serve para ampliar a memória, como lembrete para aliviar a memória). Busca-se na lista telefônica o nome, endereço e telefone de algum serviço de conserto de aparelhos quebrados; sem querer, essa leitura transmite informações sobre algo que não sabíamos antes de ler. Recebe-se uma carta ou alguém deixa um recado que deve ser lido por outro familiar ao chegar; sem querer, transmite-se informação sobre outra das funções da língua escrita (serve para comunicar-se a distância, para dizer algo a alguém que não está presente no momento de se escrever a mensagem) (FERREIRO, 2011, p. 19-20).
\end{abstract}

Todos esses conhecimentos que um infante recebe, ao relacionar-se com seus familiares letrados, são inacessíveis para os alunos que pertencem a famílias sem instrução. 
Essas informações sobre as funções sociais da língua escrita são consideradas pelas escolas como algo já conhecido. Agindo desta forma, as instituições de ensino fecham os olhos para os alunos mais necessitados, escondendo-lhes as diversas utilidades da língua escrita nas situações do cotidiano.

Ferreiro (2011) acredita que a escrita é considerada, na maior parte das escolas, como algo que possui valor em si mesmo; importante dentro da escola, para que os estudantes passem de ano, e importante para quando os alunos virarem adultos. Porém, esta maneira de entender os valores da língua escrita não adianta para convencer os alunos sobre as inúmeras serventias do código escrito no dia a dia. Pois, segundo este pensamento, a língua escrita não possui nenhum valor para a vida do aprendiz fora da escola. Saber que o conhecimento do código escrito da língua vai servir para o estudante, quando este tornar-se adulto, é muito vago para que o infante dê importância. É preciso que fique claro para os alunos que a língua escrita só tem importância na escola, por causa da sua importância fora da escola.

Se os estabelecimentos escolares mostrarem para os discentes motivos claros e palpáveis para o aprendizado da leitura e da escrita, tais aprendizes sentir-se-ão verdadeiramente estimulados a progredir nesta área. Com o desejo de avançar nessas habilidades sendo aguçado pela consciência das probabilidades de uso da língua escrita, os estudantes mirins, certamente, se empenharão ao máximo para que consigam atingir seus objetivos. Referente ao que foi dito, é interessante lembrar:

Quando a criança aprende a ler por si mesma, o prazer de poder fazê-lo torna-se maior. Quando pode escrever e deseja escrever será porque essas letras serão lidas, serão interpretadas por outras pessoas. Para aprender a escrever tem que sentir a necessidade de comunicar sua observação, seu sentimento, seu conhecimento a si mesma ou a alguém. Assim como cada criança tem seus próprios desenhos, seus próprios modos de expressão oral, tem sua própria maneira de se expressar na forma escrita (GÓMEZ e TERÁN, 2014, p. 153-154).

Para que a criança possa se desenvolver nas práticas da leitura e da escrita, primeiramente, ela precisa entender para que servem essas habilidades na vida real. Além disso, o infante precisa acreditar na sua capacidade de se expressar na forma escrita. Os docentes devem agir sempre de forma a encorajar o potencial de cada aluno. Pois, se os estudantes tiverem a consciência das utilidades da leitura e da escrita e forem estimulados a produzir, o aprendizado virá no momento certo. 


\title{
Principais Dificuldades na alfabetização de crianças autistas
}

Uma das grandes metas da educação escolar de hoje em dia é saber acolher todos os alunos, os ditos "normais" e os "especiais", de maneira que todos sejam beneficiados com progressos intelectuais e sociais. Neste estudo, vamos nos deter nas possíveis dificuldades que os docentes podem enfrentar com a alfabetização de crianças autistas. Para que estes problemas com a alfabetização de autistas mirins sejam discutidos, faz-se necessário citar:

\begin{abstract}
O autismo é um transtorno grave, que acomete a sequência e qualidade do desenvolvimento infantil, caracterizado por alterações sociais e de comunicação e por interesses restritos, fixos e intensos e comportamentos repetitivos. Os critérios mais recentes para o diagnóstico estão descritos na quinta versão do Manual Diagnóstico e Estatístico de Transtornos Mentais, DSM-V, no qual é definido com "Transtorno do Espectro do Autismo". O termo "espectro" foi utilizado para indicar a heterogeneidade da manifestação e do grau de acometimento dos sintomas. Isso significa que uma pessoa com autismo pode ser bem diferente de outra pessoa com autismo e que há uma variedade no perfil das pessoas afetadas. Pensando em extremos, pode-se ter uma pessoa com autismo muito comprometida, com dificuldades graves de interação social, que não fala, que apresenta muitas alterações comportamentais e déficits cognitivos significativos, assim como outra pessoa com autismo com sintomas tão brandos, que fala, lê, escreve e interage bem socialmente, que um olhar leigo pode não perceber que a pessoa tem autismo. Essa variedade no perfil das pessoas com autismo tem que ser considerada quando se analisa o ensino de habilidades complexas, como é o caso do ensino de leitura (GOMES, 2015, p. 15).
\end{abstract}

O autismo é um transtorno mental que apresenta uma ampla variedade de sintomas, que podem se manifestar em graus muito variados de pessoa para pessoa. É de grande importância conhecer os sintomas que se apresentam nas crianças autistas que estão prestes a serem alfabetizadas, além de procurar descobrir o grau de acometimento destes sinais.

As habilidades da leitura e da escrita, por serem habilidades complexas, exigem da criança muitos pré-requisitos. Sendo assim, é essencial que o docente analise seus alunos autistas de maneira detalhada, para que possa descobrir a melhor forma de fazê-los desenvolver estas habilidades.

Para que os professores obtenham sucesso na alfabetização de crianças autistas, antes eles precisam analisar se estas crianças já adquiriram certas habilidades mínimas. O infante acometido de autismo precisa já estar apto para realizar tarefas simples até o fim, para dar nomes a figuras e a vogais, entre outras coisas, para que, só então, consiga aprender a ler e 
escrever. Sendo assim, se o docente perceber que a criança autista ainda não consegue realizar estas atividades de nomear vogais e nomear figuras, por exemplo, ele terá que ensiná-las primeiro, e só depois poderá trabalhar com a criança as habilidades da leitura e da escrita.

As crianças autistas apresentam maior dificuldade para se comunicarem e interagirem socialmente. Este fato faz com que estes infantes especiais, certamente, sintam bem mais dificuldades no processo de alfabetização. Por este motivo, é interessante que se procure iniciar a alfabetizar estas crianças mais cedo. Pois, assim, elas terão mais tempo para desenvolverem as habilidades da leitura e da escrita. E dessa forma, estes alunos especiais poderão conseguir acompanhar seus colegas "normais", na escola regular. Sobre este assunto, pode-se mencionar:

[...] Como muitas crianças com autismo podem apresentar dificuldades nesse processo, é recomendável que o início da alfabetização ocorra precocemente (entre 4 e 5 anos), antes das crianças típicas (sem autismo) de mesma idade. A estratégia de começar a alfabetizar antes se justifica na lógica de que se a criança com autismo apresentar dificuldades nesse processo, ela terá mais tempo para aprender. Assim, se ela começar a ser alfabetizada aos 4 anos e demorar 2 anos para aprender a ler, quando ela tiver aprendido a ler, aos 6 anos, coincidirá com a idade que os colegas dela estarão lendo, o que aumenta muito a probabilidade da criança com autismo acompanhar o conteúdo escolar, permanecer e progredir na escola comum ao longo dos anos. Caso contrário, se o processo de alfabetização começar aos 6 anos, na mesma época dos colegas típicos, e a criança com autismo apresentar dificuldades em aprender a ler, inevitavelmente ela ficará atrasada em relação aos colegas, o que comprometerá o acompanhamento de todo o conteúdo escolar, já que todas as disciplinas dependem da leitura (GOMES, 2015, p. 16).

Para que a criança autista consiga se desenvolver de maneira saudável numa escola de ensino regular, ela necessita de um acompanhamento especializado na idade pré-escolar. Este acompanhamento pode ser feito por um profissional especializado ou até pelos próprios pais, que procurem obter informações precisas sobre este problema.

Os professores precisam entender que as crianças autistas possuem maneiras próprias de serem estimuladas, para que consigam aprender. Isso exige que o docente dedique atenção especial a cada criança autista, para que possa descobrir a melhor maneira de provocar-lhes o interesse pelo assunto e, consequentemente, atraiam a aprendizagem.

No ensino da leitura, os professores de crianças autistas precisam entender que estas crianças apresentam muitas vezes o pensamento visual bem mais forte do que o pensamento em palavras. Isso quer dizer que, provavelmente, será bastante útil para o aprendizado destes 
infantes a associação de palavras a figuras correspondentes. Em virtude do que foi dito sobre a aprendizagem da leitura das crianças autistas, é conveniente ressaltar:

- Deve-se levar em conta que, muitas vezes predomina o pensamento visual, como em fotos (e não em palavras).

- Para ensinar os sons, é útil usar desenhos: por exemplo, um desenho de uma chave, para o "ch" e um gato para o som de "g".

- Cartões de memória e livros com desenho são usados para que as palavras inteiras sejam associadas às fotos. É importante ter a foto e a palavra impressa no mesmo lado do cartão;

- Ensine nomes: a criança deve escutar, pronunciar a palavra e ver a foto e a palavra impressa simultaneamente. Os nomes podem ser as palavras mais fáceis de aprender, porque permitem associar uma imagem rapidamente à palavra;

- Ensino dos verbos: manter uma placa que diz "pular" e você vai pulando e dizendo "saltar". Outra opção é desenhar as palavras com letras que representam a ação, por exemplo: "cair" teriam letras que caem e "correr" teria letras que pareceriam estar correndo (GÓMEZ e TERÁN, 2014, p. 547).

\section{Considerações Finais}

Para estimular crianças autistas à leitura, o professor deve, enquanto lê para estas crianças, parar nas partes mais emocionantes, levando-as a ler a frase seguinte. Dessa forma, estes alunos especiais estarão praticando a leitura sem que para isso sintam-se pressionados. Assim, o docente estará plantando no seu pupilo a vontade de ler, a percepção de que ler é interessante.

Com relação à escrita de crianças autistas, existe um problema muito comum, que é a dificuldade na coordenação motora fina. Para as crianças autistas que apresentam esta característica, desenvolver a habilidade da escrita possivelmente será um grande obstáculo a ser vencido. Em muitos casos estas crianças terão a escrita ilegível.

Topczewski (2011) já referia que as crianças com alterações da coordenação motora fina e global, bem como com falta de destreza, tendem a apresentarem maiores dificuldades na escrita. Escrevem de modo ilegível e, frequentemente, são chamadas à atenção quanto ao empenho para a realização das suas tarefas. Por conta de tais dificuldades motoras, normalmente não conseguem contornar suas dificuldades por si mesmas, comprometendo seu emocional, que implicará em interferências no seu rendimento escolar. 
Como já foi dito, as crianças autistas que possuem a coordenação motora fina comprometida, muito provavelmente, devem ter problemas na escrita. Nestes casos, não será produtivo que os pais e/ou os professores fiquem ressaltando que a criança precisa melhorar a letra. Pois, assim, elas poderão sentir-se incapazes, quando, mesmo com seus esforços, não conseguirem aperfeiçoar a grafia. $\mathrm{O}$ que os docentes devem fazer é procurar outros meios de incentivar estes alunos a desenvolverem esta habilidade.

É muito importante que o professor observe bastante estas crianças, a fim de encontrar a melhor forma de estimulá-las. A interação entre educador e educando é fundamental para que se descubra a maneira mais adequada de impulsionar o estudante autista rumo à habilidade da escrita. Pois, muitos desses infantes não conseguem controlar bem o movimento de suas mãos. E o docente precisa encontrar meios de fazer com que este fato não leve os alunos especiais a desistirem desta habilidade tão útil. Uma estratégia sugerida por Gómez e Terán $(2014$, p.548) diz respeito ao fato de que, por conta de "...muitas crianças autistas apresentarem problemas com o controle motor de suas mãos. Escrever bem com letra cursiva é difícil para elas. Isso pode ser frustrante. Para reduzir a frustração e ajudar a aproveitar a escrita, deixe-a escrever no computador. A digitação é mais fácil”"

No ensino da escrita para crianças autistas, o computador pode aparecer como um recurso bastante motivador. Pois, como muitas delas têm dificuldade em controlar o movimento das mãos, fica muito difícil conseguirem fazer letras bem desenhadas. E o computador vai diminuir bastante o esforço das crianças, além de lhes proporcionar o prazer de escrever de forma mais clara e rápida, através da digitação.

Os docentes precisam cada vez mais interagir com os seus alunos, tanto os considerados "normais" como os "especiais". Pois, todos eles possuem particularidades que se percebidas e trabalhadas corretamente poderão ocasionar grandes diferenças no processo de aprendizagem escolar. As potencialidades e as limitações de cada aluno precisam ser conhecidas pelos seus educadores, para que estes possam encontrar a melhor forma de direcionar cada um ao desenvolvimento social, intelectual e psicológico desejado. 


\section{Referências}

BITTENCOURT, Zoraia Aguiar; CARVALHO, Rodrigo Saballa de; JUHAS, Sílvia; SCHWARTZ, Suzana. A compreensão leitora nos anos iniciais: Reflexões e propostas de ensino. Petrópolis, RJ: Vozes, 2015.

CUNHA, Eugênio. Autismo na Escola: um jeito diferente de aprender, um jeito diferente de ensinar. 3. ed. Rio de Janeiro: Wak Editora, 2015.

FERREIRO, Emília. Com todas as letras. 17. ed. São Paulo: Cortez, 2011.

GOMES, Camila Graciella Santos. Ensino de leitura para pessoas com autismo. Curitiba: Appris, 2015.

GÓMEZ, Ana Maria Salgado; TERÁN, Nora Espinosa. Transtornos de aprendizagem e autismo. São Paulo: Grupo Cultural, 2014.

HOUAISS, Antônio; VILLAR, Mauro de Salles. Dicionário Houaiss da Língua Portuguesa. Rio de Janeiro: Objetiva, 2001.

IZQUIERDO, Iván. Memória. Porto Alegre: Artmed, 2002.

MARCUSCHI, Luiz Antônio. Produção textual, análise de gêneros e compreensão. 3. ed. São Paulo: Parábola Editorial, 2008.

MARQUES, Eugenia Portela de Siqueira (Org.). Políticas públicas educacionais: novos contextos e diferentes desafios para educação no Brasil. Curitiba, PR: CRV, 2013.

NUNES, Terezinha; BUARQUE, Lair; BRYANT, Peter. Dificuldades na aprendizagem da leitura: teoria e prática. 7. ed. São Paulo: Cortez, 2011.

ORRÚ, Sílvia Ester. Autismo, linguagem e educação: interação social no cotidiano escolar. 3. ed. Rio de Janeiro: Wak Editora, 2012.

RODRIGUES, Janine Marta Coelho; SPENCER, Eric. A Criança Autista: um estudo psicopedagógico. 2. ed. Rio de Janeiro: Wak Editora, 2015.

TOPCZEWSKI, Abram. Aprendizado e suas desabilidades: como lidar?. 3 ed. São Paulo: Casa do Psicólogo, 2011.

Como citar este artigo (Formato ABNT):

SAMPAIO, Caroline M..; OLIVEIRA, Gislene F. O Desafio da Leitura e da Escrita em Crianças com Perturbação do Espectro do Autismo. Id on Line Revista Multidisciplinar e de Psicologia, Julho de 2017, vol.11, n.36, p.343-362. ISSN: 1981-1179.

Recebido: 17.07.2017

Aceito: 18.07 .2017 